\title{
"Just-in-Time Learning"
}

\author{
Mr. Hemanta Kr. Baruah \\ (M.A. from Dibrugarh University, India)
}

\begin{abstract}
The concept of 'Just-in-time' learning, derives from the Industry, refers the learner centred information delivery system which will replace the structured education massively undervalues the role of teachers in designing the "courses" of intellectual development and the role of others in forming conceptual knowledge. Educator reformers who use "just-in-time learning" are often those who advocate learner-directed, constructivist modes of learning in contrast to information delivery systems or programmed learning tutorials. 'Just-in- Time' learning based on customized educational content, active learning, fluid time \& place for students. The Just-in-time Learning facilitates primary information sources, which will eliminate the need for knowledgeable mediated guidance. It is based with assumption that learners understand what they need, where to find it, and how to use it. In 'Just-in-Time' learning model; - student centered projects, ease of access to instructional tools and tutorials \& authentic tasks--are important ingredients in the design of learning environments.
\end{abstract}

Submitted Date 11 June 2013

Accepted Date: 17 June 2013

\section{Introduction}

Education implies a plan that integrates learning into larger intellectual frameworks that will serve the learner in immediate and generative contexts. This requires dynamic teacher-student interactions around an integrated course of knowledge and skills, with the structure influenced by forces in the economy, academy and community. While technical tools can replace some of the routine tasks of delivering information at the moment of need, this work should not be confused with designing a "course" of intellectual development, providing intellectual guidance and monitoring intellectual understandings. Communication technology can widen the educational dialogue increasing access to other teachers, students, and professionals forming "learning communities" that extend beyond individualized learning and classroom teaching.

\section{Concept \& Definition}

The concept of or the phase "Just in Time Learning" is borrowed from Industry through which trainings are given to the workers when and where they need it. Rather than sitting through hours of traditional classroom training, the users can track into Web-based tutorials, interactive CD-ROMs and other tools to obtain just the information they need to solve problems, perform specific tasks or quickly update their skills.

According to Wind and Reibstein, the new model achieves its goals by moving from standardized to customized content, from discrete time and place to anytime and anyplace delivery, and from passive lecture models to interactive and applied learning. Instead of squeezing managers into the constraints of educational programs, the new model focuses on designing education tailored to the needs of students.

Wind and Reibstein say that the primary shifts in the new paradigm occur along three dimensions:

㙉 From Standardized to Customized Educational Content: Where traditional programs offer standardized content calcified in specific courses the new paradigm should offer customized knowledge tailored to the backgrounds, interests, learning styles and motivation of the student.

㙉 From Passive to Active Learning: The classroom model of education and online programs are based on a broadcast model in which knowledge from the presenter is communicated to the student. The new model is active, experiential learning in which students are presented with real-world problems and challenged to find solutions in context.

㙉 From Fixed to Fluid Time: The new technology allows students to learn anytime, anyplace and in any increment of time. Institutions need to change their educational models to deliver this just-in-time learning. 


\section{Importance}

The Just-in-time Learning concept brings changes in the present communication and delivery system of learning resources. Here, teachers are less important. The active learners collect knowledge according to their choice, urgency \& necessity from the worldwide showcase of information.

The Just-in-time Learning facilitates primary information sources, which will eliminate the need for knowledgeable mediated guidance. It is based with assumption that learners understand what they need, where to find it, and how to use it.

Here, Diagram 1 represents the traditional models of education/ information delivery system and Diagram 2 represents the Just-in-time learning model/ system.

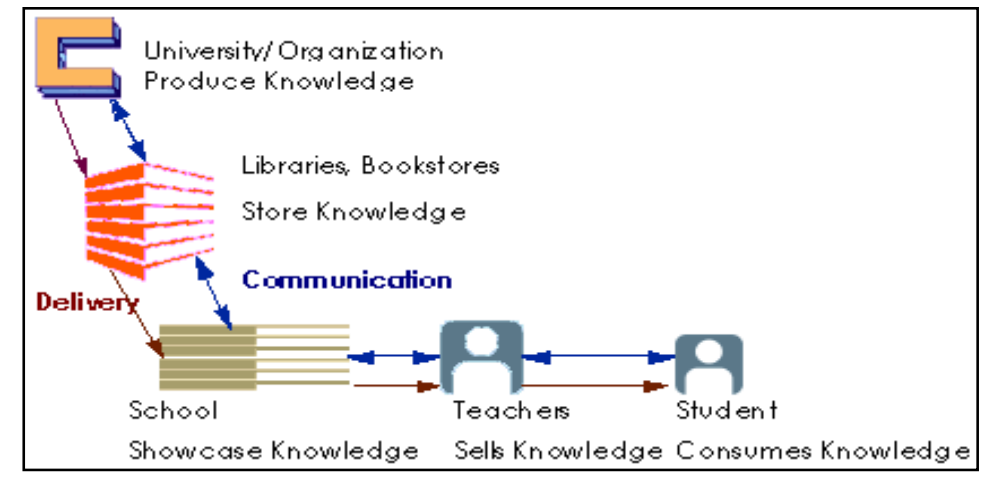

Diagram 1 : Traditional model of education/ information delivery system

Knowledge is produced in universities and organizations (factories), stored in textbooks and learning materials (warehouses), distributed to schools (stores), and delivered to students (consumers). Teachers, like knowledgeable salespersons are cast in a role of matching the needs of the students with the information resources. In many cases, they adjust the timing and organization of the delivery of the information but accept the content as determined by others. The lines of delivery are marked by the single direction arrow in Diagram 1. The two-directional arrows represent the hierarchical system of information sharing. Students and teachers talk about classrooms learning; teachers, school administrators, parents and the community discuss school needs; administrators interact with suppliers; and suppliers talk with producers.

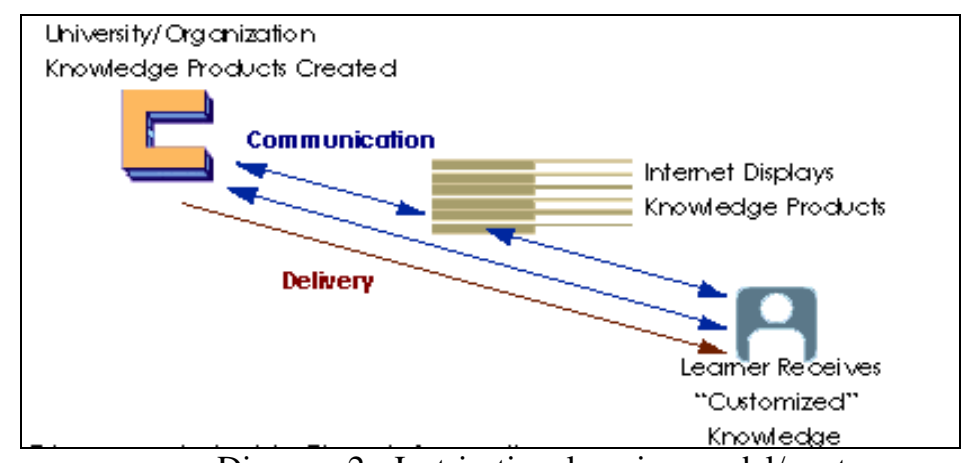

Diagram 2 : Just-in-time learning model/ system

Just-in-time learning conjures up an educational system that responds rapidly and flexibly to changing societal needs. Concepts, ideas, theories, learning tools are "delivered" as they are needed to solve real-world problems. The Internet makes it possible for learners to have contact with knowledge producers and to access information when and where they need it with less dependence on schools or teachers to mediate the access (Diagram 2).

\section{Characteristics Of Just-In-Time Learning}

Just-in-time learning suggests a highly individualist model of learning with the following dimensions: 1.1 Learner-Control :

'Just-in-time' learning implies that the learner's need is what drives the delivery of information. Educator reformers who use "just-in-time learning" are often those who advocate learner-directed, constructivist modes of learning in contrast to information delivery systems or programmed learning tutorials. They are not 
focused on delivery of information as much as on the skill that the learner must have to find the information that they need. Student learning is described as a process of constructing, elaborating and modifying representations of knowledge (Piaget, 1952; Bruner, 1961).

Students need guidance and assessment by skilled teachers. Projects need to be placed in larger contexts. Students need help in understanding how their project work relates to the larger field and to the community of people who are involved in creating, organizing and preserving knowledge. Building knowledge is a community activity.

\subsection{Time Independent and Place-Independent Access :}

Just-in-time learning is time and place-independent. The learner can access information when and where it is needed. Computers linked to the Internet provide this flexibility of access because it connects to vast collections of information and tools. Any group or individual can make digital information (photos, sounds, text, images) available to anyone who wants this information, at any time, and from any place. This is the feature that leads some to suggest that teachers will no longer be needed to organize the learning experience (Craig, 1966; Twigg 1994). The claim is that students will "learn how to learn" and will be able to pursue their interests and projects independently, with little need for teachers.

Ready access to rich informational resources from many different perspectives increases the need for skilled educational direction from teachers. Students need to learn how to evaluate information and information sources, what other resources are available, and how their work integrates with that of others to create a comprehensive understanding of a field of study.

\subsection{Functional Use of Informational Resources :}

Just-in-time learning suggests that knowledge is a stockpile of discrete ideas, concepts or tools that can be delivered as needed. It also assumes that ideas only have value in terms of their functional use in solving specified problems. Knowledge is not built from the needs of individuals; it is a process of weighing many different perspectives, of thinking beyond what is needed for the current activity. Information resources need to be examined from the multiple perspectives of the community and analyzed in ways that lead to comprehensive integrative learning.

The Internet is a stunning collection of global knowledge, with distributed control by experts and communities. This information is available to more people, more quickly, and with less effort. At a superficial level, this increases our independence from particular places and people. This is the point that is made by those who argue that just-in-time learning gives us a new way to think about education.

\subsection{Applicability in Different Levels/ Stages :}

With the knowledge base rapidly expanding, the traditional model of teaching and learning is at a breaking point. There are far too many students for one teacher. There is far too much content for any single teacher to master. The tensions in this model are different at different levels of schooling. In elementary schools, where the focus is on the learners, the tension appears in finding a single teacher who can provide rich, extensive, multi-subject learning experiences. In the secondary education, the tension results from have a large number of single subject teachers working with different groups of students hourly. In these schools, class members are grouped by age and ability to be as similar as possible. They are expected to work independently to master the content in the curriculum. Just-in-time learning suggests that students can work more independently with less need of teachers.

\subsection{From Classrooms to Learning Communities :}

The claim that "just-in-time learning" tools will make it possible for students to pursue independent learning within a computer-delivered personal learning plan is not consistent with changes that are taking place in our society.

Rather than using new communication and computer technology to further individualize learning, classrooms can be organized into learning communities with students, teachers, and community members all playing vital roles in directing the course of education. The premise that just-in-time learning should or will lead to more individualize learning is not the only possible outcome. The opposite is also possible--that these tools will transform classrooms into learning communities.

Learning communities recognize that students arrive with different skills, at different ages, with different experiences and interests and build this diversity into the learning context. In a learning community, students learn to work in teams and learn how to make teams work.

Internet technology provides a rich format for the larger community to participate in the education of the next generation. Past technologies (print, photography, film and computers) have made it possible for many people to share their ideas with students without actually entering the school, but only in a one-way transmission 
mode of communication. With communication on the Internet, it is possible for students to interact with many more people and ideas, in some cases through multi-media interaction. Transforming the classroom into a learning community makes it possible for many more people to be a part of the learning process in an open and continuing dialogue.

\subsection{From Textbooks to Primary Sources :}

Textbooks are an accommodation to economic necessity. While it is preferable to use primary source materials in classroom, neither school nor class libraries are extensive enough to contain the necessary collections. Textbooks blend many different points of view and information together into one source that can be provided to each student.

With access to the Internet, primary source data of all kinds can form the basis of instruction and research economically. With the help of these and other multi-media resources, teachers can use primary sources in their classroom presentations.

\subsection{From Direct Observation to Remote and Extended Observation :}

It is, and will remain, important for students to use their observations of the world as part of their investigations. Dewey, concerned by the rapid growth of technology of the last century, feared that direct learning experiences would be replaced by a poor substitute, book learning:

$\square \quad$ As societies become more complex in structure and resources, the need for formal teaching and learning increases. As formal teaching and training grows, there is a danger of creating an undesirable split between the experience gained in direct association and what is acquired in school. This danger was never greater than at the present time, on account of the rapid growth in the last few centuries of knowledge and technical modes of skill. (Dewey, 1916, p. 9)

Today these same words are echoed by a new generation of educators. Projects designed today, using the computer as a research tool, send students into the physical and social world to collect observations, measurements, surveys, and other data using appropriate scientific tools. Telecommunication networks make it possible for them to then exchange, analyze, and discuss this information with their peers from around the world.

\subsection{From One Expert to a World of Experts :}

Communication tools make it possible for people anywhere in the world to be a part of a classroom lesson. Increased human resources extend the topics that students can explore. Distance education is also providing flexible online materials that share information in a different format than traditional classroom lectures. Videotaped demonstrations and explanations give learners have a high degree of control over the time, location and method of study, and make it possible for teachers to work with students in distance locations. Multiple modes of delivery can augment time spent in class and communication technology can make it possible for group work to take place from individual terminals.

\subsection{Designing the Course of Learning, A Communal Activity :}

In "Just-in-Time" learning model, following three components are important for designing learning environments-

- $\quad$ student centered projects

- $\quad$ ease of access to instructional tools and tutorials

- authentic tasks.

However, the premise that the overall effort is to individualize instruction is not the only possible outcome. Increasingly we are coming to understand learning as a social interactive process.

With the emerging Networld and with it more powerful communication tools, the classroom walls no longer need to isolate students from the community.

The tools that are new making a difference in classroom are those that help students to connect and create. The connections are both inside and outside of the classrooms where experts of all ages can be a part of the resources for learning. And the ability to create is what makes it possible for every student to share what he or she discovers with others. Teachers are likely to continue to play a vital role in helping students to shape, evaluate, and share ideas.

\section{Conclusion}

"Just-in-time" learning is based on a metaphor that cast learners in the role of highly knowledgeable consumers of knowledge. Rather than decrease the need for teachers, I see technology is increasing access to, and need for, teachers. Communication technologies is transforming classrooms into learning communities in which students learn and teach and in which teachers (some in the classrooms and some from distant locations) 
teach and learn. My central argument is that just-in-time learning technology will increase the need for skilled teaching and teachers, and not serve to marginalize teaching.

\section{References}

[1] Hunter, Beverly, Learning and teaching on the Internet: Contributing to educational reform (In Kahin, B. and Keller, J. (eds.) Public Access to the Internet. MIT Press, 1995)

[2] Lave J. \& Wegner, E., Situated Learning: Legitimate Peripheral Participation (Cambridge, MA: Cambridge University Press,1991)

[3] Oppenheimer, T., The computer delusion (Atlantic Monthly, July, 260, 45-62,1997)

[4] Pea, R., Seeing what we build together: Distributed multimedia learning environments for transformative communications (Journal of the Learning Sciences, 3(3), 219-225, 1994)

[5] Riel, M., Learning in the Networlds of Tomorrow (http://www.iearn.org/ webtour/2, 1997)

[6] Rohwedder, W. J., \& Alm, A., Using Computers in Environmental Education: Interactive Multimedia and On-Line Learning (http://eelink.umich.edu/Computers/pp.html\#Additional Tools, 1997)

[7] Sambataro, M., Just-in-Time Learning (INDUS, Year Of Publication, Computerworld,2000) 